\title{
Sex Contextualism
}

\author{
Sarah S. Richardson*
}

\begin{abstract}
This paper develops the conceptual framework of "sex contextualism" for the study of sexrelated variables in biomedical research. Sex contextualism offers an alternative to binary sex essentialist approaches to the study of sex as a biological variable. Specifically, sex contextualism recognizes the pluralism and context-specificity of operationalizations of 'sex' across experimental laboratory research. In light of recent policy mandates to consider sex as a biological variable, sex contextualism offers constructive guidance to biomedical researchers for attending to sex-related biological variation. As an alternative to and critique of biological binary sex essentialism, sex contextualism contributes to current debates in philosophy of biology, feminist science studies, and social ontology on the construction of categories of gender/sex differences in scientific research.
\end{abstract}

\section{Keywords \\ sex $\bullet$ sex essentialism $\bullet$ gender $\bullet$ preclinical research $\bullet \mathrm{SABV}$}

\section{Introduction}

This essay proposes a contextualist framework for conceptualizing the construct of 'sex' in labbased biomedical research. Biological concepts of sex matter because they serve as a framework for preclinical research design involving sex-related biological variables, including the questions asked, the materials selected for study, and how data are aggregated and interpreted. They also matter because the biological construct of 'sex' is a site of power and politics. The recent introduction of institutional mandates requiring consideration of sex as a biological variable in all government-funded preclinical cell, tissue, and model organism research is a case in point (Clayton and Collins 2014). Biomedical claims about sex differences are also regularly cited in arenas such as legal recognition of gender minorities, sex testing in sports, and rising rightwing antifeminist movements around the globe (Ha et al. 2014; Pape et al. 2020).

An important proviso: This is not an essay about gender, meaning roles and norms traditionally ascribed to males and females. Nor is this essay about gender or sexual identity in the sense at stake in transgender recognition and human rights movements. That is, I embrace an

*Department of the History of Science, Harvard University, 1 Oxford St, Science Center 371, Cambridge, MA 02138 USA, srichard@fas.harvard.edu

Received 22 January 2021; Accepted 11 August 2021 doi:10.3998/ptpbio.2096 
analytic distinction between 'sex' and 'gender.' In actual practice, sex and gender interact and co-constitute each other along multiple dimensions - a point that I return to in the conclusion.

For the moment, my aim is to give sex its due as a theoretical construct. In biomedical research, sex is often seen as the simple side of the sex-gender equation, easily defined by reference to a short list of objective materialities, i.e., hormones, chromosomes, gonads, and genitals (Sex \& Gender 2020). Gender, on the hand, is perceived as a context-dependent social concept. Here, I analyze "sex" in biomedicine as a similarly context-dependent construct, tracing its uses and meanings within the pragmatics of biomedical research: in particular, in the design, interpretation, and communication of laboratory-based experimental research.

I begin by presenting a set of five representative examples of how sex is materially and pragmatically operationalized in biomedical research. Next, I describe current debates among scientists, funding agencies, and research journals over how to attend to sex as a biological variable in biomedical research. With reference to this debate, I contrast two approaches to conceptualizing sex as a biological variable: binary sex essentialism and sex contextualism. I then develop the framework of sex contextualism. Finally, I outline some of the constructive work that embracing sex contextualism both within and beyond the laboratory might advance.

\section{Operationalizing 'Sex' in Biomedical Research: Examples}

What does studying sex in biomedical research actually look like? Experimental biomedicine uses model systems and idealized conditions in the laboratory to elucidate relationships of causal dependence. Researchers use cell lines, tissues, and model organisms from C. elegans to mice to human systems. Frequently, pragmatics ranging from cost, sample availability, skill set, model organism, and disciplinary background drive decisions about how to study a particular problem.

This sampling of cases across a variety of research fields - including drug metabolism, neuroscience, stress and pain studies, and wound science-and model systems - microchips, roundworms, mice, and cell lines-illustrates that there are many ways of operationalizing sex in biomedical research. These examples show, first, that male-female comparisons represent only one kind of operationalization of sex as a variable in biomedical research. Second, they demonstrate that many operationalizations of "male" and "female" are limited in their generalizability to all males and all females, and that many claims about male-female sex differences in a model system are limited in their generalizability to embodied humans. Finally, they illustrate that biological material in preclinical biomedical research often does not have a clear, stable, or functionally important sexual identity.

\section{EVATAR: A microchip model of the female reproductive tract}

EVATAR is a multi-organ, micro-physiological system replicating the female reproductive tract, funded by the NIH Office of Research on Women's Health. The microchip is proposed as a platform for assessing sex differences in drug metabolism prior to human trials:

She's innovative. She's 3-dimensional. She's made out of human cells. She has a functional reproductive tract that includes an ovary, fallopian tube, uterus, and cervix. She also has a liver, and the channels necessary to pump nutrients between her organs. She produces and responds to hormones, and has a normal, 28-day hormone cycle. She can metabolize drugs. She can tell you how a drug may affect fertility in women or if it is toxic to the liver. And, she fits in the palm of your hand. She's the future of drug testing, in women and in personalized medicine. And her 
name is EVATAR. Just as Eve is the mother of all human, EVATAR is the mother of all micro-humans. (McKinnon 2020)

EVATAR embraces a particular idea about metabolically-relevant sex differences: that they are primarily contained to the female reproductive system. In this way, EVATAR provides a stark example of an "operationalization." Sex differences are captured by a female reproductive system distilled into a set of modules on a microchip. Notably, the system is not entirely human; it uses mouse ovarian tissue, acknowledging that mouse reproductive systems differ in important ways from primate and human systems. Each module contains a living tissue mimicking a different organ of the reproductive tract, as well as the liver. A culture medium can be circulated within each organ module, between organ modules, and throughout the entire system, enabling the controlled and biomimetic distribution of biomolecules such as metabolites and hormones (Tayag 2017; Xiao et al. 2017).

The case of EVATAR shows how the study of sex in biomedical research involves laboratorytailored materials and technologies such as genetically engineered and cloned strains, reproductively arrested model organisms, cell lines fused with cancer cells to reproduce indefinitely, and technologies of measurement and quantification which are themselves not hypothesis-free.

\section{"Roundworm puberty": Model organisms and the genetics of sexual differentiation}

A more routine example of the laboratory operationalization of sex in biomedical research is offered by a 2019 study, "Timing mechanism of sexually dimorphic nervous system differentiation" (Pereira et al. 2019). The study reported on genetic studies in cells in the fourth stage of larval development in the roundworm C. elegans, just before it becomes sexually active. Researchers identified genes involved in controlling the timing of sexual differentiation of undifferentiated cells in the C. elegans nervous system. Those genes are expressed for a short period, initiating a regulatory process that shapes neural structure and function. A 2019 university press release on the study, titled "Genes That Drive Male-Female Brain Differences and Timing of Puberty," was accompanied by an image of a human male and female side-by-side, divided by a half-blue, half-pink brain. The release touted that the genes driving male-female brain differences in timing of puberty may have been discovered and asserted that the genetic finding may help reveal how differences in men's and women's behavior are "hardwired in our brains."

This extrapolation, of course, overlooks critical limitations in generalizing about sex-related processes from one species to another. In C. elegans, there are two sexes, males and hermaphrodites (which produce both sperm and eggs and can self-fertilize). Males are extremely rare and are also difficult to produce and maintain in the laboratory. In nature, they compose $0.1-0.3 \%$ of the population. The genetics of sex in roundworm is different also than sex in a human male-female system. As opposed to humans with a Y-chromosomal sex determining system, C. elegans use an $\mathrm{X}$-dosage system (X:autosomes) to determine sex (they are $\mathrm{XX} / \mathrm{XO}$; we are $\mathrm{XX} / \mathrm{XY}$ ). Furthermore, whereas in humans, the second $\mathrm{X}$ is inactivated in females, equalizing $\mathrm{X}$-dosage between males and females, in C. elegans self-fertile female hermaphrodites express both Xs at depressed levels.

Differences in sex-related processes are not restricted to the comparison of roundworms and humans. Research comparing sex-biased gene expression across a wide range of species and lineages demonstrates that sex-biased gene expression is not highly conserved across species, including closely related ones (Naqvi et al. 2019). University press releases aside, because of this diversity of sexual systems across species, sex-related variables require rigorous contextualization and validation before extrapolating from common laboratory model organisms to humans (Eliot and Richardson 2016). 
Observer sex-effects in rodent stress and pain research: Laboratory environment as a mediator of sexrelated variables

The laboratory environment can interact with and modify sex-related processes in biological study materials. For example, a 2014 study found that the sex of the human observer in experimental stress research using rodents can affect measures of anxiety and pain (Sorge et al. 2014). Mice were infected with an inflammatory agent to experimentally induce pain and filmed while a human observer sat one meter away. When a human male but not a human female experimenter was present, rodent corticosterone stress hormone increased at levels equivalent to those induced by a 15 -minute restraint or a 3-minute forced swim. The presence of a male observer was also a pain analgesic. Researchers believe that it is unlikely that mice have evolved to respond differently to human males. More likely, mice react with a stress response to cues of the presence of an unfamiliar male conspecific in their territory. If some component of this sexspecific odor signal is shared among mammalian species, then this could explain why human males generate this response in mice.

The study concluded by suggesting that "standard laboratory practice should account for experimenter sex when investigating any phenomenon possibly affected by stress" (Sorge et al. 2014). It further advised that sex of observer be reported in all rodent studies and that any procedures that involve pain be done by males due to the analgesic effect of the male observer (see also Katsnelson 2014). Notably, while sex of observer emerges as an important variable in these studies, and the pathway involved is a sex-related one, the outcome is not a finding of sex differences in the rodents. Rather, a sex-related pheromonal androgen-sensing pathway in both male and female mice is induced by the presence of a human male.

The sex-effect of human male observers in rodent stress research is just one example of how laboratory environment can influence animal biology and behavior, affecting the scientific conclusions that are drawn. Many other well-documented laboratory environmental conditions specifically confound the exploration of sex-related variables in rodents, including group vs. individual and same-sex vs. mixed-sex caging, light/dark cycle schedules, estrogens in diet, bedding, cages, and water bottles, and common vivarium pathogens (Mauvais-Jarvis, Arnold, and Reue 2017).

\section{The "Battlefield Estrogen Injector": Constituting sexed subgroups across age and estrus cycle}

Sex-related variables are not always best studied by comparing males and females. In 2015, a research group at the University of Alabama studying wound infections was surprised to find that female mice resisted wound sepsis without any treatment. But when they repeated the experiment, the finding did not hold up: the untreated female septic mice all succumbed to infection. Upon investigation, they found that the two groups of female mice had been at different stages in their estrous cycles. By chance, the first group had been in the proestrus phase, when estrogen levels are at their peak, and the second group in the diestrus phase, when they are low.

The researchers' subsequent proposal, of estrogen injections as a treatment for wound trauma, massive loss of blood, and sepsis, to be used on the spot in case of major injury, won a US Department of Defense competition for treatments that could extend survival in the face of massive loss of blood. "Female sex hormone may save injured soldiers on the battlefield," announced a headline about the winning proposal for a "Battlefield Estrogen Injector" (Hansen 2015).

While estrogen is here described as a "female hormone," the premise of the battlefield estrogen injector is that a dose of the estrogen $17 \beta$-estradiol (E2) will protect males as well as females against septicemia assuming similar functions, pathways of uptake, and therapeutic efficacy. The

๑ OPEN ACCESS - PTPBIO.ORG 
relevant treatment groups are not defined by sex, but by estrogen levels. As Chaudry and coauthors write, "A number of studies have reported gender dimorphism in terms of response to trauma, shock and sepsis. However, the advantageous outcome following trauma-hemorrhage in females is not due only to sex. Rather, it is due to the prevailing hormonal milieu of the victim" (Bösch, Angele, and Chaudry 2018, 35).

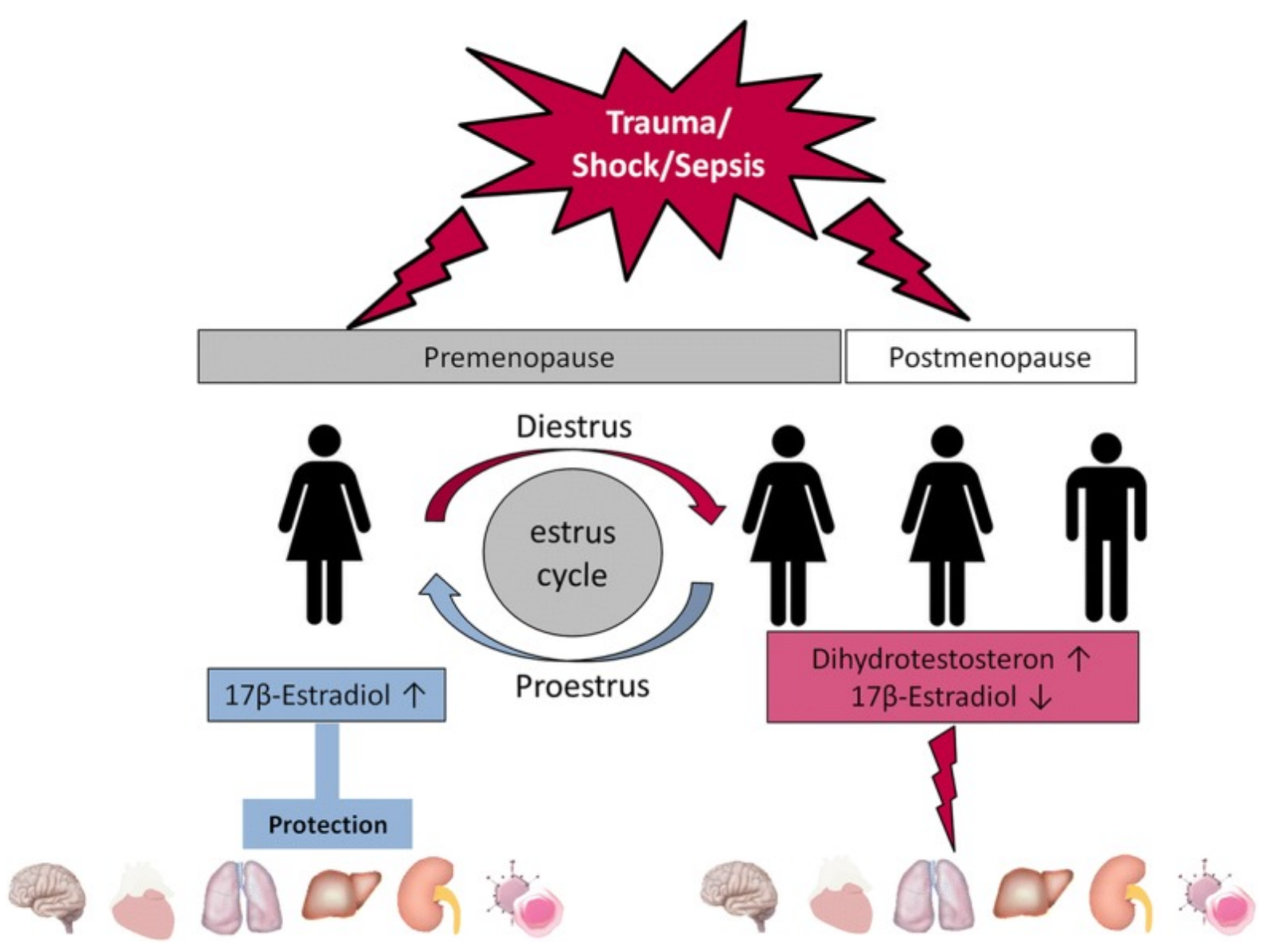

Figure 1: Four "sexes" across two treatment groups for estrogen wound therapy (Bösch, Angele, and Chaudry 2018), Creative Commons Attribution 4.0 International License.

As Figure 1 illustrates, this model of estradiol's role in improving resistance to wound sepsis predicts at least four "sexes" across two treatment groups: females who are in the proestrus phase, females who are in the diestrus phase, females who are postmenopausal, and males. Other considerations that might mediate the effect of estrogen on wound sepsis may include male adiposity, natal males and females taking exogenous hormones, prepuberty, pregnancy/lactation, and other nonovulatory conditions. In sum, for this wound sepsis research, materially, estrogen is a sex-related biological variable but not a "female" one-and to understand its therapeutic effects, comparing males and females is inadequate.

\section{HeLa: A 'female' cell line}

Sex is not a salient or meaningful variable in all materials. The well-known HeLa cell line was derived in 1951 from the tumor of Henrietta Lacks, a Black woman in Baltimore, Maryland. Cell lines are transformed cells that are hybridized so they do not die out. HeLa tumor cells were cultured and immortalized to provide standardized research material for scientists. They have 
generated an astonishing 74,000 scientific publications, largely in the field of cancer research (Landecker 2000; Skloot 2010). Notably, this includes male-specific conditions such as prostate cancer. But the fact that an enormous body of twentieth-century biomedical research on human disease has been done on a "female" cell line should not necessarily leave men concerned. Indeed, it makes littles sense to attribute a "sex" to cells or cell lines fashioned for biomedical research (Ritz 2016).

Each cell line has a distinct history and biology. For example, HeLa has been shown to contain not only the genome of Henrietta Lacks, but also the genomes of several viruses, and elements of the genomes of some of the researchers who have come into contact with the cell line. It has been suggested, as a result of this and many other analyses of the HeLa cell line, that it should not even be considered human anymore, but its own species (Lucey, Nelson-Rees, and Hutchins 2009). Relatedly, an analysis of male-derived cell lines, originally from XY male human cells, found that at least $40 \%$ of them have lost their Y chromosome (Shah, McCormack, and Bradbury 2014). To this picture, we can add that in cell research, growth media generally contain fetal bovine serum, with a mix of pregnancy hormones and hormones from both male and female fetuses, and Phenol Red, a weak estrogen mimic (Ritz 2016). In sum, in many foundational laboratory materials fashioned for research, such as cell lines, sex is neither a stable nor a binary attribute.

\section{Binary Sex Essentialism in Institutional Mandates to Consider Sex as a Biological Variable}

The examples above offer a picture of varied materially-instantiated, pragmatic definitions of sex found in experimental assemblages and opportunistic observations in a laboratory context. However, this contextual variation is obscured in conceptualizations of sex as a biological variable mobilized in current institutional efforts to mandate the study of sex in preclinical biomedical research.

\section{"Sex as a Biological Variable" mandates}

Today, the biomedical sciences are in the midst of a large-scale global push for mandates to include biological materials from "both" sexes and to disaggregate data by sex. Over the past decade, guidelines for the consideration and reporting of sex as a biological variable (SABV) have been introduced by leading funding agencies, journals, and pharmaceutical companies.

In 2016, the NIH, which funds $\$ 30$ billion in research annually, began implementing a policy requiring the study of sex as a biological variable in preclinical medicine. The policy requires biomedical researchers who study everything from roundworms to zebrafish, and from mice to humans, to include male and female materials in their research and to outline a plan to analyze differences between male and female cells, tissues, and animals in their funding proposals.

As the NIH decision tree guidance on SABV to grant reviewers (Figure 2) shows, the core requirement of the policy is that researchers include materials or specimens from "both" sexes and report data disaggregated by sex-meaning male and female. That is, sex is operationalized in one way in this policy: as the binary of male and female.

\section{Inclusion and difference}

The NIH's SABV policy is the outcome of a long-term institutional effort to develop the fields of sex-based biology and gender-specific medicine, championed over the past three decades by 


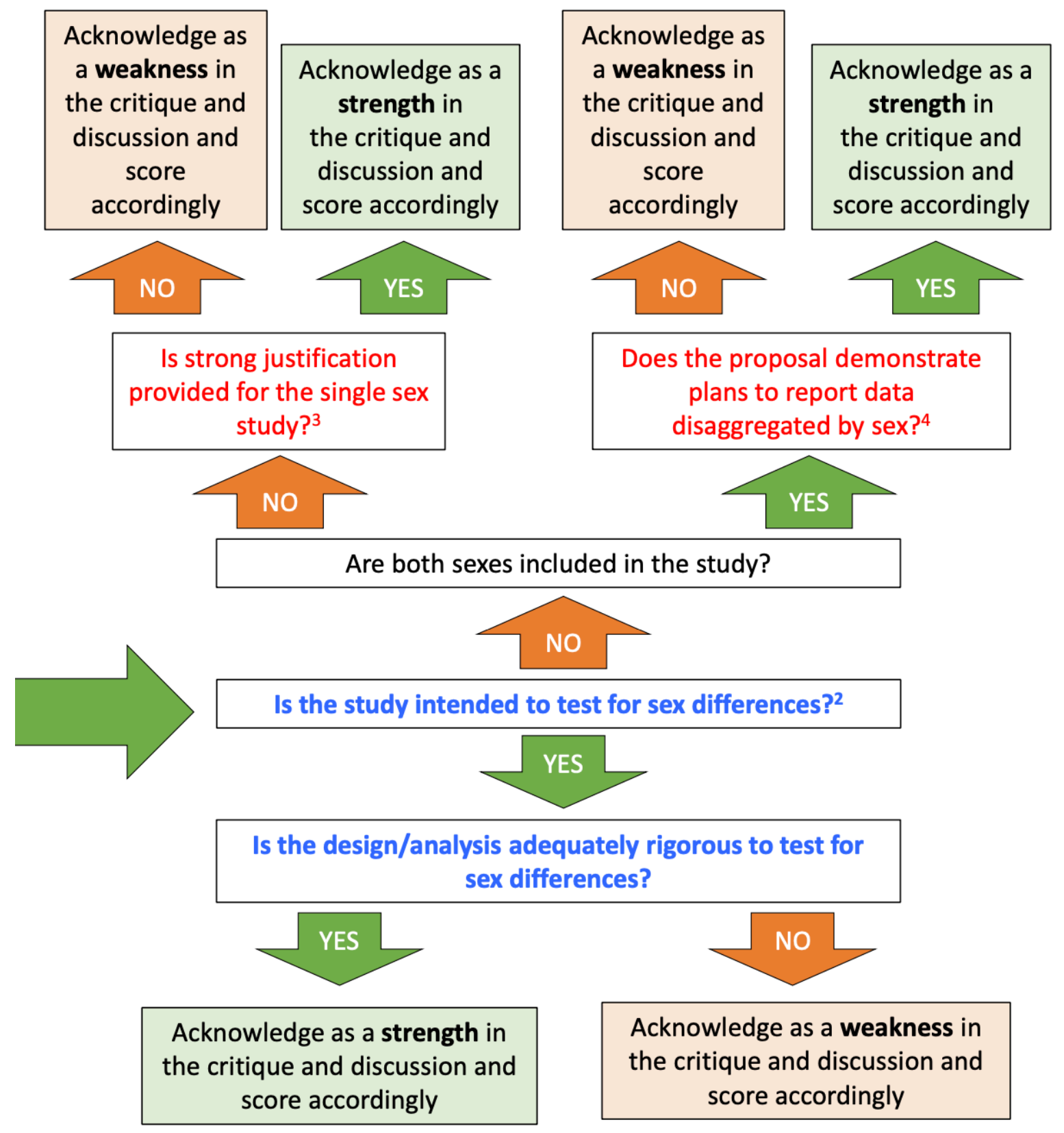

Figure 2: Reviewer Guidance to Evaluate Sex as a Biological Variable (SABV) (National Institutes of Health 2016).

women's health advocates (Epstein 2007; Richardson 2013). An earlier landmark achievement of this effort was the 1993 mandate to include women in the final drug trials before a drug goes to market. Since then, advocates have pressed for the requirement to be extended to laboratory practices beyond the clinical, including in the broad expanse of experimental animal model, cell, and molecular biology research. While this research is termed "preclinical" because of potential applications for understanding human health and disease, in practice it is often also basic science research, exploring fundamental processes and causal mechanisms in biology.

To justify the policy, advocates and NIH officers appeal to gender equity, arguing that addressing men's and women's health disparities requires mandating the study of sex differences 
in all studies at every level down to the tissue and cell: "Female Mice Liberated for Inclusion in Neuroscience and Biomedical Research," announced one article by a leading neuroscientist celebrating the introduction of the new preclinical mandate to study sex differences (Prendergast, Onishi, and Zucker 2014).

This form of advocacy for sex-inclusion in medical research involves a precarious dance between claims for inclusion based on political representation and equity and assertions of essential biological difference, as medical sociologist Steven Epstein demonstrated in his book, Inclusion: The Politics of Difference in Medical Research (2007). Inclusion policies, writes Epstein, "involve the practice of bargaining for inclusion for a group of research subjects in medical research by claiming the possibility or probability of medically relevant biological differences."

As Epstein points out, while documenting sex differences may be important, overemphasizing sex differences can lead to sex stereotyping in the clinic and in the laboratory. This risks improper treatment of patients who do not conform to a group mean. A focus on sex can also obscure biological variables other than sex, such as age or body size, which may explain a differential distribution of a condition across genders/sexes. Policies requiring the study of sex differences through male and female comparisons, Epstein warns, can reinforce "a cultural tendency to accept scientific claims that support a view of males and females as profoundly and systematically different." They also "perpetuate a view of sex differences as principally biological and not also cultural, leading to a potentially dangerously inaccurate understanding of the causes of sex disparities" (Epstein 2007, 253-4).

\section{Omnipresence, Essentialism, and Binarism: "Every cell has a sex"}

Strong essentialist statements about human sex differences characterize the supporting literature for new SABV mandates. The consistent message is that sex is a fundamental and powerful causal agent producing variation human biology, and that the differences between males and females are large and thoroughgoing. "I don't know the question, but sex is definitely the answer!" reads one paper title by policy advocates (Fuller and Insel 2014).

The mantra that "Every cell has a sex" has, over the last decade, come to represent the central message of SABV mandate advocates. Fulfilling the cause of women's health, these advocates claim, is not limited just to research on women's reproductive organs and diseases-it extends to every organ, and every cell (Pollitzer 2013). "Every cell has a sex," Dr. Janine Clayton, head of the National Institutes for Health (NIH) Office of Research on Women's Health argues. "Each cell is either male or female, and that genetic difference results in different biochemical processes within those cells" (Rabin 2014).

The propositions that "every cell has a sex-male or female" and that sex as a biological variable is sufficiently considered when biological materials derived from "both" sexes are included in research reflect an essentialist and binary biological concept of sex. According to this view, all cells intrinsically have sexes because of the presence of sex chromosome complement and other sex-related molecular markers. This conception of sex is unwedded to reproductive function. Rather, maleness and femaleness are essences represented by the presence or absence of a discrete set of biochemical factors. On this view, since every organ or tissue will bear the hormonal and genetic traces of the organism as a whole, sex is a pervasive attribute, omnipresent in the biological material of sexually reproducing species, and any biological object of analysis, whether a whole organism or a single cell, that contains these factors is male or female. 


\title{
4 Sex Contextualism: An Alternative to Biological Sex Essentialist Approaches to SABV
}

\author{
What is sex, and what do we want it to be?
}

Let me begin by invoking the metaphysician and social ontologist Sally Haslanger's "ameliorative" approach to theorizing social concepts, which she has so generatively applied to thinking about race and gender, in order to think here about 'sex' (Haslanger 2000). An ameliorative approach starts from practice-what people actually do-and then asks what we want to do. The goal is not ideal theory — that is, to say "sex is this" - but real theory, i.e., "here's what people say sex is, and here's how we can tweak that to be more like what we think it ought to be." Of race and gender, Haslanger asked, "(What) Are They? (What) Do We Want Them to Be?" Similarly, I ask,"What is sex, and what do we want it to be?"

In constructing an ameliorative account, Haslanger advises us to consider "the pragmatics of our talk employing the terms in question. What is the point of having these concepts? What cognitive or practical task do they (or should they) enable us to accomplish? Are they effective tools to accomplish our (legitimate) purposes; if not, what concepts would serve these purposes better?" Haslanger notes that "neither ordinary usage nor empirical investigation is overriding, for there is a stimulative element to the project: this is the phenomenon we need to be thinking about" (Haslanger 2000, 224).

So, what do we want in our concept of "sex" in biomedical research? The following pragmatic and ameliorative suppositions guide my own thinking. First, we need to understand each other: our concept of sex should be reflective and well-defined, without conflating or slipping between different meanings of the term. Secondly, we need to meet our explanatory needs. Biomedical researchers working with sexually reproducing species must be able to attend to variation related to sex-differentiated developmental pathways in these species. Third, what we say about sex needs to be consistent and updateable with respect to with judicious interpretations of the best available empirical evidence. Fourth, our concept of sex needs to be sensitive to the ethical implications of claims-making about the biology of sex differences. This point acknowledges that concepts and words have political and social implications: sex is not just a biological concept, closed behind the laboratory doors; sex is also a central construct in our social ontologies (Haslanger 2015). Fifth, our concept of sex should acknowledge the pragmatics of language and not require an unrealistic revision of vocabularies that extend across different areas of expertise and social arenas.

\section{Sex contextualism}

Sex contextualism is the simple view that the definition of sex and sex-related variables, and whether they are relevant in biomedical research, depends on the research context (see Box 1). This research context may include pragmatic interests, observational constraints, interacting or mediating environmental variables, characters of the species or strain, developmental stage of the research organism or materials, and level of biological analysis-for example, cell, tissue, organism, and community. Whether and how "sex" is operationalized will be specific to each experimental setting. On this view, sex-related biological variables are material factors that vary among sex subclasses, however a researcher has defined them. Whether sex is a relevant subclass, whether such subclasses are understood as discrete or continuous, how many subclasses of sex are specified, and what constitutes a sex and a sex-related variable depends on research context. 
Sex contextualism embraces the view that no single component or set of components specifies sex across biomedical research programs. According to sex contextualism, there is no "sex itself." There is only sex as pragmatically constituted in an observational frame.

A helpful analogy can be made here between "sex" and "age." Age is a critically important variable in biomedical research. Everyone has an unchanging year of birth; everyone has an age. The need to consider age, however, depends on research context. When age is considered as a biological variable, it is operationalized in plural ways across research materials and disciplines. It is also now commonplace to hear biomedical researchers speak of the distinction between the chronological and biological age of an individual, an organ, a tissue or a cell (Horvath and Raj 2018). A heart can be chronologically 72 years old but have a biological age of 40 . The telomeres of a 20-year-old's DNA can show the weathering of a 50-year-old. Within one body, one might have tissues of varying biological ages. Age itself is not a biological variable, but the biomarkers that make up age in each of these different tissues and levels of biological analysis can be understood as causally related to age, conceptualized in a variety of ways. We speak of "age-related variables," understanding that what these are in any instance will be specific to the tissue, field of research, current state of technology, and so on. This "age contextualism" is just how I propose we think of sex.

\section{Sex contextualism}

What "sex" and "sex-related variables" are, and whether they are relevant in biomedical research, depends on the research context.

1. A sex is a subclass (discrete or continuous) within the context of a biomedical research program, generally in reference to reproductive traits.

2. Sex-related biological variables are material factors (components, processes, mechanisms, systems) that vary among sex subclasses.

3. Whether "sex" is a relevant subclass, how many subclasses of sex are specified, and what constitutes a "sex" and a "sex-related biological variable," depends on research context.

4. Research context may include pragmatic interest, observational constraints, interacting or mediating environmental variables, characters of the species or strain, developmental stage of the research organism or materials, and level of biological analysis (for example, cell, tissue, whole organism, or community).

\section{Box 1: Sex contextualism}

Sex contextualism calls on researchers to contextually define sex-related biological variables and to justify their choices in how they operationalize sex. I stress that sex contextualism neither denies the reality of sex as an evolved developmental pathway with many implications for biology nor the possibility that male-female comparisons may at times be an apt research design for studying sex. Sex contextualism is consistent with the perspective that sex-related variables are present in most biological materials and that sex is relevant to areas of biomedical inquiry beyond reproduction-related traits and tissues. However, while sex-related factors may be present 
throughout biological systems and levels of analysis, context matters. In many contexts, sexrelated variables in biological materials may not be functionally related to reproduction, or to phenotypic sex differences. On a contextualist account, mere presence of an XX/XY chromosome complement, for example, need not mark biological materials as "male" or "female" when those variables have no causal relationship to sex phenotype as defined within a particular research program.

\section{Implications for practice: "Sex as a biological variable" policies}

Cellular, genetic, neuroscientific, and endocrinological science now make clear that the systems of the body are networked and that sex-related variables are present in, and may be important or influential in, many different tissues not restricted to the reproductively differentiated ones that have been a traditional area of focus in sex difference research. For practitioners, sex contextualism offers a way of conceptualizing sex-related biological variables that is consistent with a molecular, networked, whole-body understanding of the biology of sex but does not entail binary biological sex essentialism (McCarthy and Arnold 2011; de Vries and Forger 2015).

Sex contextualism also better describes plural scientific practices around the operationalization of sex in a laboratory-based setting, highlighted in the examples at the start of this paper, than does sex essentialism. In a survey of scientists regarding thirteen different factors that might be required by SABV policies, only one item received broad consensus as "absolutely critical": that scientists should identify the sex of the cells, tissues or animals being used (Tannenbaum et al. 2016). The survey documents significant dissensus about other items, such as whether scientists should be required to perform sample-size calculations to show adequate power for a sex-disaggregated analysis, identify the type of serum used to supplement tissue culture media, report negative findings with respect to sex differences, or detail the method for documenting and controlling the hormonal status of experimental female animals. A 2019 survey of NIH study section members tasked with implementing the NIH SABV policy similarly revealed significant dissensus in sentiment, which ranged from supportive statements that sex inclusion as "an important issue" necessary for "scientific rigor and reproductivity," to queries such as, "Why is sex being singled out as the key biological variable to be considered for review purposes?", to the more critical "this is nonsense," "this ignores the complexity of sex as a biological variable," and "this policy introduces a variable that cannot be controlled for with typical budget and capacity constraints" (Woitowich and Woodruff, 14; see also Waltz et al. 2021).

Sex contextualism offers constructive guidance to researchers for the consideration of sexrelated biological variables that acknowledges the omnipresence of sex-related variables in research materials as well as this dissensus and complexity. Table 1 contrasts the prescriptions for mandates to consider sex as a biological variable that follow from a binary sex essentialist framework and a sex contextualist framework, respectively. Both frameworks affirm the importance of attending to variation produced by sex-related biological factors in biomedical research, and both appreciate that sex-related variables may be present in non-sex-specific and non-reproductive materials. But the sex contextualist does not begin with the premise that the relevant sex subclasses are "male" and "female," does not insist that presence of sex-related biological variables in biological material entails functional relevance to sex-specific biology, and does not treat "sex" as a variable in itself. 


\begin{tabular}{|c|c|c|}
\hline & Binary sex essentialism & Sex contextualism \\
\hline $\begin{array}{l}\text { Central } \\
\text { concern }\end{array}$ & $\begin{array}{l}\text { Studies using material derived } \\
\text { from one sex may not be general- } \\
\text { izable to the other sex. }\end{array}$ & $\begin{array}{l}\text { Sex-related variables produce } \\
\text { variation between and within } \\
\text { sex-defined classes in a context- } \\
\text { sensitive manner. Comparisons } \\
\text { of males and females may not } \\
\text { be generalizable to all males and } \\
\text { all females. Findings of sex dif- } \\
\text { ferences in one model system or } \\
\text { species may not be generalizable } \\
\text { to other systems or species. }\end{array}$ \\
\hline $\begin{array}{l}\text { Omnipresence } \\
\text { of sex-related } \\
\text { variables }\end{array}$ & $\begin{array}{l}\text { All biological systems and mate- } \\
\text { rials have a sexual identity, either } \\
\text { male or female. }\end{array}$ & $\begin{array}{l}\text { Presence of sex-related biologi- } \\
\text { cal variables in biological material } \\
\text { does not entail a causal relation to } \\
\text { sex-specific biology, nor does it } \\
\text { necessarily warrant attribution of } \\
\text { male or female sex to that mater- } \\
\text { ial. }\end{array}$ \\
\hline $\begin{array}{l}\text { Policy } \\
\text { guidance }\end{array}$ & $\begin{array}{l}\text { Biomedical research, including } \\
\text { preclinical studies in cell lines, } \\
\text { cells, tissues, and model organ- } \\
\text { isms, should account for sex by } \\
\text { including male and female sub- } \\
\text { jects/material and reporting any } \\
\text { differences between these two sub- } \\
\text { groups. }\end{array}$ & $\begin{array}{l}\text { Variation produced by sex-related } \\
\text { factors should be considered in } \\
\text { biomedical research, motivated } \\
\text { by and interpreted within a well- } \\
\text { specified research context. Male- } \\
\text { female comparisons may not be } \\
\text { necessary or sufficient to capture } \\
\text { sex-related biological variation. }\end{array}$ \\
\hline
\end{tabular}

Table 1: Sex essentialism vs. Sex contextualism: sex inclusion policies 


\section{Broader Implications}

As the biologist Stacey Ritz, looking at the question of cell sex, argues, "in the moment of defining an experimental setup, the practices of experimental laboratory work instantiate a material definition of sex" (Ritz 2016, 320). Citing feminist science theorist Karen Barad, she continues, "In doing so, we are engaging in 'interested instances of power...with real material consequences' for how we understand the impact of sex on health" (Ritz 2016, 320; see Barad 1996; for critical discussions of the NIH SABV policy, see Pape 2021; Eliot and Richardson 2016; Richardson et al. 2015).

Beyond the arenas of health and basic biological research, biomedical frameworks for conceptualizing sex also have consequences in the arena of law and public policy. Globally, antifeminist, anti-LGBTQ movements increasingly appeal to biological science as the basis of traditional gender roles and for nonrecognition of gender minorities (Butler 2020). An emblem of this movement, the so-called "\#FreeSpeechBus" (Figure 3), toured Europe and North America in recent years. The bus is adorned with images of a pair of children, one with pigtails and a dress, with the chromosomes XX and XY marked over their genital areas. "It's biology! Boys are boys and always will be, girls are girls and always will be," reads the bus's billboard (Hawkins 2017).
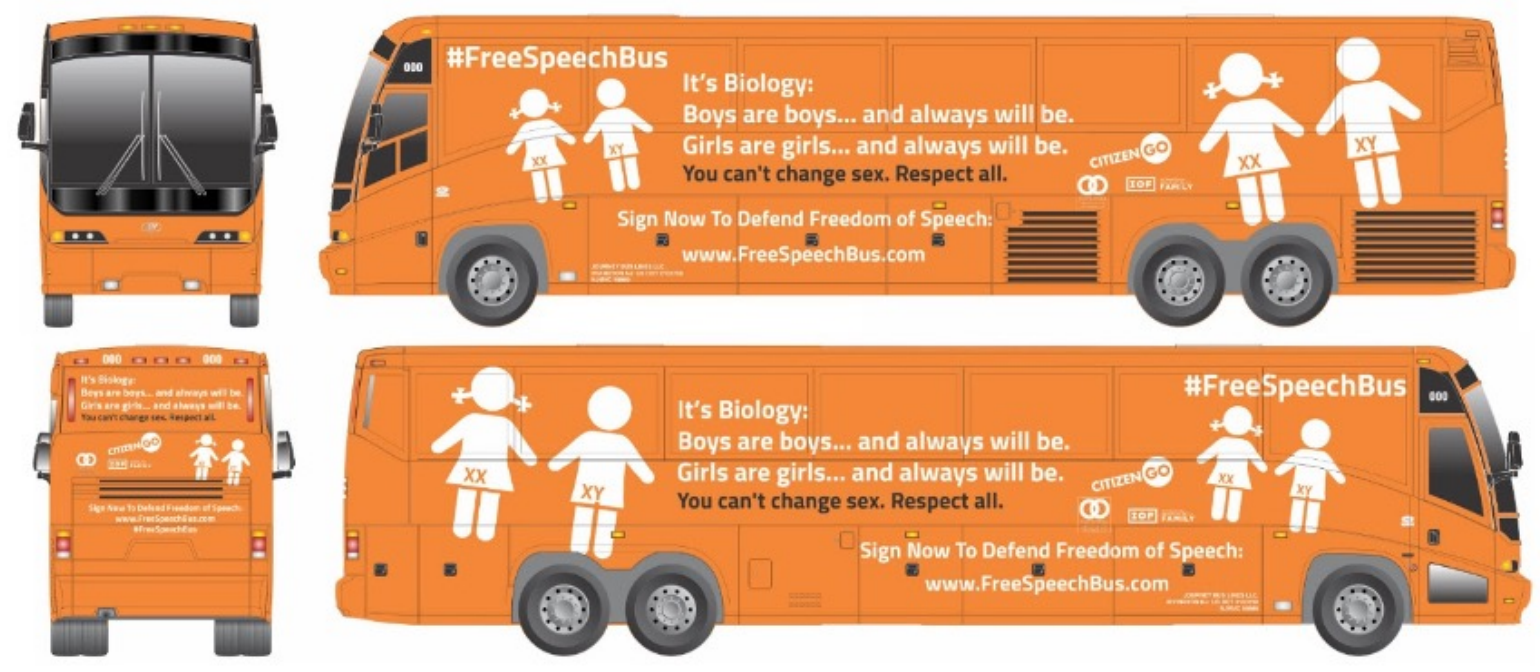

Figure 3: Free Speech Bus, 2017; Image from The National Organization for Marriage and CitizenGO.

In Hungary, Poland, Brazil, and the United States, concerted attempts to institute binary biologically essentialist definitions of sex in the law, appealing to science as warrant, are currently underway. Analysis by legal scholar Maayan Sudai found extensive appeals to biomedical definitions of sex in US state legislative bills aiming to prevent transgender and nonbinary people from using their preferred bathroom (Sudai 2019). In 2018, the United States Health and $\mathrm{Hu}-$ man Services Administration (HHS) announced its intention to specify that sex and gender will be defined by genitals at birth or, lacking that, genetics, a move that would exclude transgender and intersex people from civil rights protections and access to health provisions under the Affordable Care Act. Citing biomedical literature, including the NIH SABV mandate, the HHS memo argued that "sex means a person's status as male or female based on immutable biological traits identifiable by or before birth," claiming that this legal definition is necessary for "ascertaining a person's sex on a biological basis that is clear, grounded in science, objective, and administrable" (Green, Benner, and Pear 2018). 
The authors of these efforts are binary biological sex essentialists. They believe that sex is defined by a set of binary, fixed variables that are facts of biology, found in nature across species and ecologies, uncontroversially "scientific," and omnipresent throughout the body so that every tissue at every level of biological organization can be characterized as male or female.

This social backdrop demands of researchers that they carefully reflect on their choice of conceptual framework for understanding sex as a biological variable. By emphasizing the contextspecificity of scientific operationalizations of sex-related biological variables, sex contextualism offers an alternative framework to researchers than that of essentialist, binary, biological sex. In this way, sex contextualism may be fruitful and clarifying not only for biomedical researchers, but in promoting constructive critical dialogue among interpreters of the science of sex-related biological variation across diverse social arenas.

\section{Conclusion: Sex Contextualism as a Theoretical Framework for the Rigorous Study of Sex-Related Biological Variables in Biomedicine}

Sex-related variables operate at many levels of biological analysis from the molecular to the whole organism. But are cells and organs aptly and usefully conceptualized as "male" and "female"? And if a non-sexually-reproducing bit of biological material can have a sex, what precisely is sex?

Biological sex contextualism attends to the materiality of sex without a prior commitment to a particular ontology of sex. For the sex contextualist, sex-related variables gain biological meaning and emerge as relevant or not within the context of a particular research program. On this view, male and female comparisons are just one way of operationalizing sex in actual practice. "Male" and "female" do not mean the same thing in all contexts, nor are these the only subclasses that could be termed "sexes." What constitutes sex in biomedical research, according to this account, varies depending on context.

Sex contextualism better describes what biomedical scientists do when they attend to sexrelated variables than does sex essentialism. Thus, many researchers will find in sex contextualism a recognizable account of their already-formed but perhaps implicit understanding of the meaning of sex-related biological variables in lab-based biomedical research. But it is not only a descriptive account. Sex contextualism can help biomedical scientists design, interpret, and communicate their research without falling into binary sex essentialism. Sex contextualism is ameliorative, prescriptive, and ethical in orientation, appealing to biomedical researchers to reflect on any particular operationalization of the concept of sex, and to think about its consequences both for research and for the broader arenas in which sex as a concept operates.

\section{Acknowledgments}

Thank you to the Wissenschaftskolleg zu Berlin for supporting the writing of this article and to Alex Borsa for research assistance.

\section{Literature cited}

Barad, Karen. 1996. "Meeting the Universe Halfway: Realism and Social Constructivism Without Contradiction." In Feminism, Science, and the Philosophy of Science, 161-194. Springer. 
Bösch, Florian, Martin K. Angele, and Irshad H. Chaudry. 2018. "Gender Differences in Trauma, Shock and Sepsis.” Military Medical Research 5 (1): 35. https://doi.org/10.1186/ s40779-018-0182-5.

Butler, Judith. 2020. "What Threat? The Campaign Against “Gender Ideology”.” Glocalism 2019 (3). https://doi.org/10.12893/Gicpi.2019.3.1.

Columbia University. 2019. "Genes That Drive Male-Female Brain Differences and Timing of Puberty.” Neuroscience News. Accessed Jan. 19, 2021.

Clayton, Janine A., and Francis S. Collins. 2014. "Policy: NIH to Balance Sex in Cell and Animal Studies.” Nature 509 (7500): 282-283. https://doi.org/10.1038/509282a.

De Vries, G. J., and N. G. Forger. 2015. "Sex Differences in the Brain: A Whole Body Perspective." Biol Sex Differ 6: 15. https://doi.org/10.1186/s13293-015-0032-Z.

Eliot, L., and S. S. Richardson. 2016. "Sex in Context: Limitations of Animal Studies for Addressing Human Sex/Gender Neurobehavioral Health Disparities.” J Neurosci 36 (47): 11823-11830. https://doi.org/10.1523/Jneurosci.1391-16.2016.

Epstein, Steven. 2007. Inclusion: The Politics of Difference in Medical Research. Chicago: University of Chicago Press.

Fuller, Catherine M., and Paul A. Insel. 2014. "I Don't Know the Question, But Sex Is Definitely the Answer!” American Journal of Physiology-Cell Physiology 306 (1): C1-C2. https://doi.org/10.1152/ Ajpcell.00342.2013.

Green, Erica L., Katie Benner, and Robert Pear. 2018. “Trump May Limit How Government Defines One's Sex.” The New York Times, Oct. 22, 2018, A.

Ha, N. Q. S. L. Dworkin, M. J. Martínez-Patiño, A. D. Rogol, v. Rosario, F. J. Sánchez, A. Wrynn, and E. Vilain. 2014. "Hurdling Over Sex? Sport, Science, and Equity." Arch Sex Behav 43 (6): 1035-42. https://doi.org/10.1007/s10508-014-0332-0.

Hansen, Jeff. 2015. "Female Sex Hormone May Save Injured Soldiers on the Battlefield." UAB News, Oct. 21, 2015. https://www.uab.edu/news/research/item/ 6625-Female-Sex-Hormone-May-Save-Injured-Soldiers-on-the-Battlefield.

Haslanger, Sally. 2000. “Gender and Race: (What) Are They? (What) Do We Want Them to Be?” Noûs 34 (1): 31-55. https://doi.org/https://doi.org/10.1111/0029-4624.00201.

Haslanger, Sally. 2015. “Theorizing With a Purpose: The Many Kinds of Sex.” In Natural Kinds and Classification in Scientific Practice, edited by Catherine Kendig. London: Routledge.

Hawkins, Derek. 2017. “An Anti-Transgender 'Free Speech Bus' Is Rolling Through the East Coast.” The Washington Post, March 31, 2017.

Horvath, Steve, and Kenneth Raj. 2018. "DNA Methylation-Based Biomarkers and the Epigenetic Clock Theory of Ageing.” Nature Reviews Genetics 19 (6): 371-384. https://doi.org/10.1038/ s41576-018-0004-3.

Katsnelson, Alla. 2014. Male Researchers Stress Out Rodents. Nature Nerws. https://doi.org/10.1038/ nature.2014.15106.

Landecker, Hannah. 2000. "Immortality, In Vitro: A History of the HeLa Cell Line.” In Biotechnology and Culture: Bodies, Anxieties, Ethics, edited by Paul E. Brodwin, 53-72. Bloomington, IN: Indiana University Press.

Lucey, B. P., W. A. Nelson-Rees, and G. M. Hutchins. 2009. "Henrietta Lacks, HeLa Cells, and Cell Culture Contamination.” Arch Pathol Lab Med 133 (9): 1463-7. 10.5858/133.9.1463. 
Mauvais-Jarvis, F., A. P. Arnold, and K. Reue. 2017. "A Guide for the Design of Pre-Clinical Studies on Sex Differences in Metabolism.” Cell Metab 25 (6): 1216-1230. https://doi.org/10.1016/j. cmet.2017.04.033.

McCarthy, M. M., and A. P. Arnold. 2011. "Reframing Sexual Differentiation of the Brain." Nat Neurosci 14 (6): 677-83. https://doi.org/10.1038/Nn.2834.

McKinnon, Kelly E. 2020. "EVATAR: The Mother of Microhumans.” Accessed 1 November. https: //www.woodrufflab.org/Evatar-MPS.

Naqvi, Sahin, Alexander K. Godfrey, Jennifer F. Hughes, Mary L. Goodheart, Richard N. Mitchell, and David C. Page. 2019. "Conservation, Acquisition, and Functional Impact of Sex-Biased Gene Expression in Mammals.” Science 365 (6450): eaaw7317. https://doi.org/10.1126/Science. aaw7317.

National Institutes of Health. 2016. "Reviewer Guidance to Evaluate Sex as a Biological Variable (SABV).” https://grants.nih.gov/grants/peer/guidelines_general/sabv_decision_tree_for_reviewers. pdf.

Office of Research on Women's Health. 2020. "Sex \& Gender." National Institutes of Health. https: //orwh.od.nih.gov/sex-gender.

Pape, Madeleine. 2021. "Coproduction, Multiplied: Enactments of Sex as a Biological Variable in U.S. Biomedicine." Social Studies of Science 51 (3): 339-363. 10.1177/0306312720985939.

Pape, Madeleine, Katrina Karkazis, J.R. Latham, and Stacey A. Ritz. 2020. "Resisting and Remaking Sex in the Petri Dish, the Clinic, and on the Track." Catalyst: Feminism, Theory, Technoscience 6 (2): $1-17$.

Pereira, L., F. Aeschimann, C. Wang, H. Lawson, E. Serrano-Saiz, D. S. Portman, H. Großhans, and O. Hobert. 2019. "Timing Mechanism of Sexually Dimorphic Nervous System Differentiation." eLife 8. https://doi.org/10.7554/eLife.42078.

Pollitzer, E. 2013. “Biology: Cell Sex Matters.” Nature 500 (7460): 23-4. https://doi.org/10.1038/ 500023 a.

Prendergast, B. J., K. G. Onishi, and I. Zucker. 2014. "Female Mice Liberated for Inclusion in Neuroscience and Biomedical Research." Neurosci Biobehav Rev 40: 1-5. https://doi.org/10.1016/j. neubiorev.2014.01.001.

Rabin, Roni Caryn. 2014. "Labs Are Told to Start Including a Neglected Variable: Females." The New York Times, May 15, 2014, 1A.

Richardson, Sarah S. 2013. Sex Itself: The Search for Male and Female in the Human Genome. Chicago: University of Chicago Press.

Richardson, Sarah S., Meredith Reiches, Heather Shattuck-Heidorn, Michelle Lynne Labonte, and Theresa Consoli. 2015. "Focus on Preclinical Sex Differences Will Not Address Women's and Men's Health Disparities." Proceedings of the National Academy of Sciences 112 (44): 13419-13420. http://www.pnas.org/content/112/44/13419.

Ritz, Stacey A. 2016. “Complexities of Addressing Sex in Cell Culture Research.” Signs: Journal of Women in Culture and Society 42 (2): 307-327. https://doi.org/10.1086/688181.

Shah, Kalpit, Charles E. McCormack, and Neil A. Bradbury. 2014. "Do You Know the Sex of Your Cells?” American Journal of Physiology: Cell Physiology 306 (1): C3-C18. https://doi.org/10.1152/ Ajpcell.00281.2013.

Skloot, Rebecca. 2010. The Immortal Life of Henrietta Lacks. New York: Crown Publishers.

Sorge, Robert E., Loren J. Martin, Kelsey A. Isbester, Susana G. Sotocinal, Sarah Rosen, Alexander H. Tuttle, Jeffrey S. Wieskopf, et al. 2014. "Olfactory Exposure to Males, Including Men, Causes 
Stress and Related Analgesia in Rodents.” Nature Methods 11 (6): 629-632. https://doi.org/10. 1038/Nmeth.2935.

Sudai, Maayan. 2019. "Toward a Functional Analysis of Sex in Federal Antidiscrimination Law." Harv. Women's LJ 42: 421.

Tannenbaum, Cara, Jaclyn M. Schwarz, Janine A. Clayton, Geert J. De Vries, and Casey Sullivan. 2016. "Evaluating Sex as a Biological Variable in Preclinical Research: The Devil in the Details." Biology of Sex Differences 7: 13. https://doi.org/10.1186/s13293-016-0066-X.

Tayag, Yasmin. 2017. Scientists Built a Vagina on a Tablet. Inverse. https://www.inverse.com/article/ 29624-vagina-female-reproductive-system-organ-on-chip-evatar

Waltz, M., K. W. Saylor, J. A. Fisher, and R. L. Walker. 2021. "Biomedical Researchers' Perceptions of the NIH's Sex as a Biological Variable Policy for Animal Research: Results From a U.S. National Survey." J Womens Health (Larchmt). https://doi.org/10.1089/Jwh.2020.8997.

Woitowich, N. C., and T. K. Woodruff. 2019. "Implementation of the NIH Sex-Inclusion Policy: Attitudes and Opinions of Study Section Members." J Womens Health (Larchmt) 28 (1): 9-16. https://doi.org/10.1089/Jwh.2018.7396.

Xiao, Shuo, Jonathan R. Coppeta, Hunter B. Rogers, Brett C. Isenberg, Jie Zhu, Susan A. Olalekan, Kelly E. McKinnon, et al. 2017. "A Microfluidic Culture Model of the Human Reproductive Tract and 28-Day Menstrual Cycle.” Nature Communications 8 (1): 14584. https://doi.org/10. 1038 /ncomms14584.

(C) 2022 Author(s)

This is an open-access article distributed under the terms of the Creative Commons Attribution 4.0 International license, which permits anyone to download, copy, distribute, display, or adapt the text without asking for permission, provided that the creator(s) are given full credit. 